\title{
Finger pad friction and tactile perception of laser treated, stamped and cold rolled micro-structured stainless steel sheet surfaces
}

\author{
S. ZHANG $^{1,2, *}$, X. ZENG ${ }^{3}$, D. T. A MATTHEWS ${ }^{2,4}$, A. IGARTUA ${ }^{5}$, E. RODRIGUEZ-VIDAL ${ }^{5}$, J. CONTRERAS \\ FORTES $^{6}$, E. VAN DER HEIDE ${ }^{2,7}$ \\ ${ }^{1}$ State Key Laboratory of Tribology, Tsinghua University, Beijing 100084, China \\ ${ }^{2}$ Laboratory for Surface Technology and Tribology, Faculty of Engineering Technology, University of Twente, Drienerlolaan 5, Enschede \\ $7522 \mathrm{NB}$, the Netherlands \\ ${ }^{3}$ Shanghai Advanced Research Institute, Chinese Academy of Sciences, China \\ ${ }^{4}$ Tata Steel, Research \& Development, PO Box 10000, IJmuiden 1970CA, the Netherlands \\ ${ }^{5}$ IK4-Tekniker, C/Ignacio Goenaga 5, Eibar 20600, Spain \\ ${ }^{6}$ Acerinox Europa SAU, Los Barrios, Spain \\ ${ }^{7}$ TU Delft, Faculty of Civil Engineering and Geosciences, Stevinweg 1, Delft 2628 CN, the Netherlands \\ Received: 23 September 2016 / Revised: 30 November 2016 / Accepted: 11 January 2017 \\ (C) The author(s) 2017. This article is published with open access at Springerlink.com
}

\begin{abstract}
Tactile perception is a complex system, which depends on frictional interactions between skin and counter-body. The contact mechanics of tactile friction is governed by many factors such as the state and properties of skin and counter-body. In order to discover the connection between perception and tactile friction on textured stainless steel sheets, both perception experiments (subjective) and tactile friction measurements (objective) were performed in this research. The perception experiments were carried out by using a panel test method to identify the perceived roughness, perceived stickiness and comfort level from the participants. For the friction experiments, tactile friction was measured by a multi-axis force/torque transducer in vivo. The perceived stickiness was illustrated as an effective subjective stimulus, which has a negative correlation to the comfort perception. No significant evidence was revealed to the connection between the perceived roughness and comfort perception, and this relationship may be influenced by the participants' individual experience, gender and moisture level of skin. Furthermore, the kinetic tactile friction was concluded as an objective stimulus to the comfort perception with a negative correlation.
\end{abstract}

Keywords: tactile friction; perception; pleasant touch; biotribology

\section{Introduction}

Tactile comfort, a concept with a mechanical, physiological and a psychological perspective, is of particular concern to industry and academia. The hedonic attributes of tactile comfort are influential to our daily life like wearing clothes, using personal care products, holding tool handles or in domestic

* Corresponding author: S. ZHANG, E-mail: s.zhang@utwente.nl appliances [1-3]. In the case of designing hand tools, the relationships of comfort descriptors and comfort factors with users' experiences have been investigated, and the relation with skin friction to enhance the comfort level of products is described in detail [4-6]. In a more prosaic case, the degree of comfort in tactile contact between the skin and stainless steel surface for domestic appliances greatly affects the quality of 
our daily life. Stainless steel is one of the most common materials used in automobile, architecture, kitchenware, medical applications, etc. However, the study of perception and friction on stainless steel material is limited. The enhancement of tactile comfort in daily interaction with stainless steel products can directly increase the customers' satisfaction by the stimulation of the somatosensory system in a positive way. A higher added value could be created by understanding the stimulus parameters and pleasantness factors [7] validated by an experimental approach for stainless steel sheet material.

A basic understanding of the skin anatomy is important to tactility-related research. The skin has a complicated structure composed of three main layers: epidermis, dermis and hypodermis [8]. Each layer has a different composition, thickness, hydration degree and mechanical properties [9]. In addition, the state and properties are a function of the body region, age, degree of hydration or nutritional condition as well [10-15]. Overall, the skin behaves in a viscoelastic, non-homogeneous, nonlinear and anisotropic manner under load.

The tactile friction can be influenced by the surface texture during the measurements. According to the work of Tomlinson et al., additional effects including interlocking and hysteresis can be added to adhesion $[16,17]$. From the psychological perspective, humans are able to distinguish multidimensional textural stimuli including sensations of roughness versus smoothness, hardness versus softness, stickiness versus slipperiness, and warmth versus coolness [18]. In this paper, the perception experiment was focused on the following three surface properties: hardness, roughness and stickiness. Stainless steel sheet samples were used with the same thermal properties and within the same hardness range, therefore, only roughness and stickiness were variables in this research.

In total, five surface textures are analyzed: four deterministic surface textures with specific geometric shapes, designed for this research, and one conventionally finished sample ( $2 \mathrm{G}$ finish) as reference. Three different surface fabrication methods, i.e., laser surface texturing, stamping (or pressing) and cold rolling were used to produce the experimental surface textures on stainless steel samples. This combination of production technologies is unique and not reported before in surface haptic related research. The objective of this research is to investigate the relationship between tactile comfort and friction, specifically for stainless steel sheet surfaces.

\section{Methods}

\subsection{Subjects and conditions}

The finger friction measurements and perception experiments were performed in a controlled laboratory having an ambient temperature of $20 \pm 1{ }^{\circ} \mathrm{C}$ and relative humidity of $50 \% \pm 10 \%$. The total number of subjects were sixteen (eight female and eight male volunteers) aged from 20 to 30 years with no known skin disease. All tests were conducted on the middle finger of the non-dominant hand to avoid any bias, because the dominant finger (index finger) of the dominant hand can have more wear of the finger ridges due to frequent daily use. No external skin care products were used prior to the experiments. The fingertips were cleaned with alcohol and air-dried for ten minutes before testing. A Corneometer CM 825 (Courage+Khazaka GmbH, Germany) was used to measure the hydration level of the skin (up to $120 \mathrm{AU}$ ) before the experiments. The range of hydration level of all subjects was 62 120 AU. The evaluation of hydration related skin types can be categorized by arbitrary units (AU) into: very dry skin (<30 AU), dry skin (30 40 AU), normal skin (40 100 AU), wet skin (100 120 AU), very wet skin (>120 AU) [19].

\subsection{Testing objects}

Five stainless steel EN-1.4301 tiles, four textured and one conventionally finished surface $2 \mathrm{G}$, were used in the tests (see Table 1 and Figs. $1 \& 2$ ). The test areas of samples in contact with fingers during sliding were approximately $30 \mathrm{~mm} \times 30 \mathrm{~mm}$. The $1 \mathrm{~mm} \times$ $1 \mathrm{~mm}$ area of each sample was measured by a threedimensional (3D) areal confocal microscope ( $\mu$ SURFmobile, NanoFocus AG, Germany) with a 20× objective (height resolution $=63 \mathrm{~nm}$ ) and a $4 \mu \mathrm{m}$ filter. According to the literature, 3D roughness parameters give more complete assessment of the roughness over the surface compared to two-dimensional (2D) roughness parameters on the flat surface structures [20]. The 3D surface 
Table 1 The surface parameters of the samples with depth $(D)$, spacing $(\lambda)$, width $(W)$, 3D surface roughness (Sa) were measured using a $3 \mathrm{D}$ areal confocal microscope ( $\mu$ SURF-mobile, NanoFocus AG, Germany).

\begin{tabular}{cccccccc}
\hline Sample name & $\begin{array}{c}\text { Fabrication } \\
\text { method }\end{array}$ & $\begin{array}{c}\text { Surface } \\
\text { texture }\end{array}$ & $\begin{array}{c}\text { Sample size } \\
(\mathrm{mm})\end{array}$ & $\begin{array}{c}\text { Depth, } D \\
(\mu \mathrm{m})\end{array}$ & $\begin{array}{c}\text { Width, } W \\
(\mu \mathrm{m})\end{array}$ & $\begin{array}{c}\text { Spacing, } \lambda \\
(\mu \mathrm{m})\end{array}$ & $\begin{array}{c}\text { Sa } \\
(\mu \mathrm{m})\end{array}$ \\
\hline 1HV90 & Stamping & Crater & $35 \times 65 \times 1$ & 20 & 50 & 50 & 0.49 \\
1 HV90-1\% & Cold rolling & Grid & $35 \times 65 \times 1$ & 20 & 50 & 60 & 1.34 \\
HDG-1 & LST & Grid & $35 \times 35 \times 1$ & 30 & 75 & 90 & 4.02 \\
LDG-3 & LST & Grid & $35 \times 35 \times 1$ & 30 & 100 & 115 & 6.56 \\
2G & Cold Rolling & - & $35 \times 65 \times 1$ & - & - & - & 0.13 \\
\hline
\end{tabular}

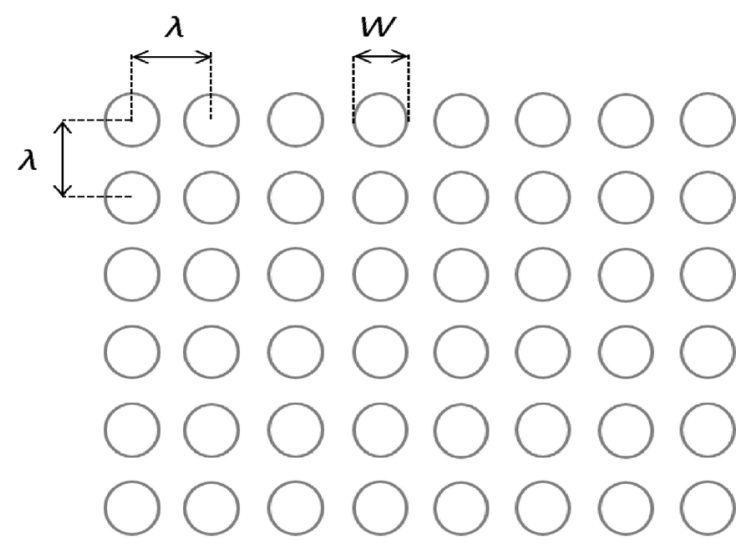

Fig. 1 Texture parameters for crater and grid structures.

roughness Sa of the texture denotes the average vertical deviation at the location of the measured surface area, and is greatly influenced by the height of pattern. Compared to the line roughness $\mathrm{Ra}$, the $3 \mathrm{D}$ surface roughness Sa is conducted in an areal measurement which is more accurate to describe the surface characteristic in roughness. Therefore, surfaces of the samples were measured in 3D surface roughness Sa in this work.

All samples were using the same stainless steel sheet material EN-1.4301 with different surface texture produced by various fabrication methods and taken from a large set of microstructured samples based on the topographical quality of the texture produced in an EU project [21]. Sample 1HV90 was fabricated by a stamping method with tools that contain the negative of a crater pattern which is hemispherical (see Fig. 2(a)). The grid pattern on sample 1HV90 with $1 \%$ elongation was produced by cold rolling with rolls that contain the negative of the pattern (see Fig. 2(b)). The low density grid pattern on sample (a)

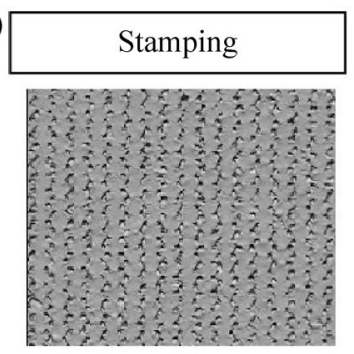

(b)

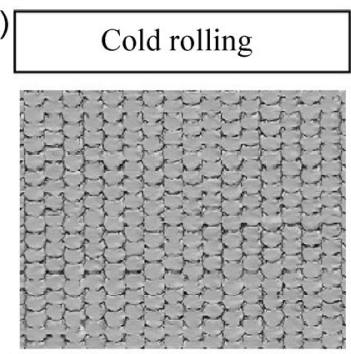

(c)

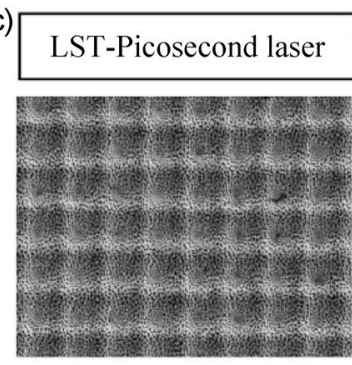

(d)

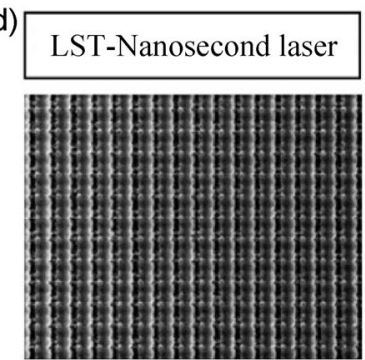

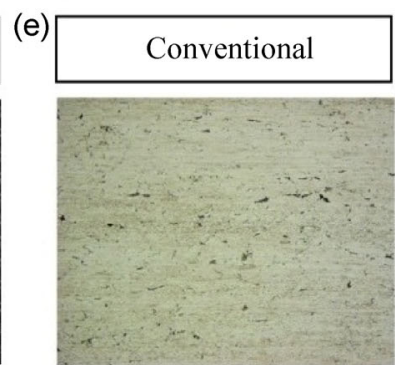

Fig. 2 SEM images of sample (a) 1HV90 (stamping), (b) 1HV90-1\% (cold rolling), (c) HDG-1 (LST-Picosecond), (d) LDG-3 (LST-Nanosecond) and (e) $2 \mathrm{G}$ (reference). 
LDG-3 (see Fig. 2(d)) was produced by direct laser surface texturing with a nano-second laser, and the high density grid pattern on sample HDG-1 (see Fig. 2(c)) was fabricated by direct laser surface texturing (LST, pico-second laser). The sample $2 \mathrm{G}$, produced by cold rolling and subsequent skin pass rolling, was used as received condition and served as a reference specimen for comparison (see Fig. 2(e)). The samples 1HV90, LDG-3 and HDG-1 are specifically designed for touch perception, and produced for the first time.

\subsection{Testing methods}

The experiments were conducted in two parts: perception experiments (subjective rating) and tactile friction measurements (objective measurement). First, the perception experiments were carried out by using a panel test method to identify the perceived roughness, perceived stickiness and comfort level from the subjects (see Fig. 3(a)). The work of Whitaker shows both vision and touch is able to contribute information to the perception of texture in an independent but complementary manner. The exposure of the object to a visual stimulus can increase or decrease the preference during the touch perception [22]. Therefore, all the participants were blindfolded to avoid vision interference on perception and focus on touch perception only. Before the perception experiments, the participants (all master students from an English-based course) were explained by the author in English, and any rising questions were answered to clear the doubts. The four samples having designed textures and one reference stainless steel samples were presented to the subjects in random order. The subjects were requested to use the middle finger of their nondominant hand to touch and slide along the sample surface toward the body. The same sliding direction was performed in the friction measurements. According to the previous study, the sliding direction to the texture can alter the kinetic tactile friction between the fingertip and the counter-surface [23]. During the perception tests, the subject had unlimited time to explore the sample before reporting a judgment. The ratings from 0 to 10 were graded by each subject to describe the level of perceived roughness, perceived stickiness and comfort. The higher number represented a greater perception of roughness. The same ten-point scale was used for the perception of surface stickiness and comfort level. The participants may have confusion about the perception of stickiness between stick-slip friction and stickiness-adhesion. Since the assessment was given during the sliding motion, it is more likely the panelists graded the perception of stickiness based on how smooth the motion is. In addition, the subjects may touch and slide the samples more than one time before the grades were given.

For the friction experiments, a multi-axis force/torque transducer (ATI Industrial Automation, Apex, NC, USA) was used to measure kinetic skin friction in vivo (see Fig. 3(b)). This apparatus, described in full detail in Ref. [23], is able to measure the outputting forces (a)

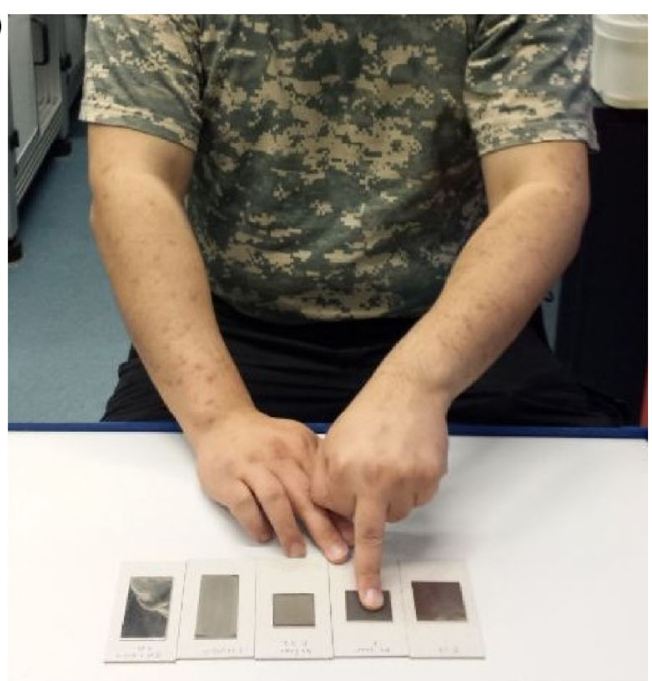

(b)

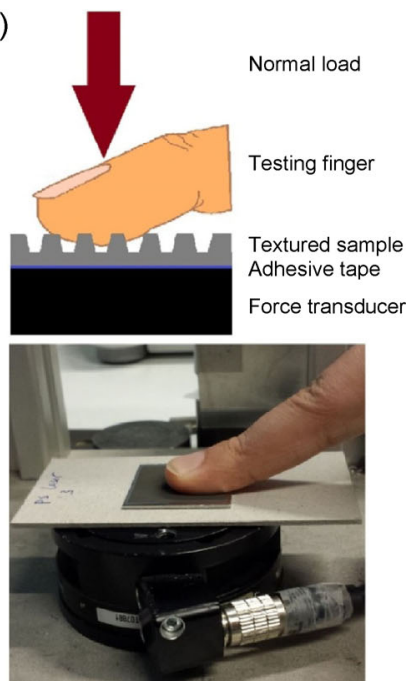

Fig. 3 (a) Perception experiment (blindfolded); (b) friction measurement set-up. 
and torques from all three Cartesian coordination $(x, y$, and $z$ ) with the resolution of $25 \mathrm{mN}$ in normal direction and $12.5 \mathrm{mN}$ in tangential direction. Double sided tape was used to firmly fix the testing samples to the top of the force transducer. The same fingers used during the perception tests were used to perform sliding motion on the samples towards the body. Each friction measurement consisted of five repetitions of sliding motion. All participants were instructed to slide in a stable and natural way with no external load. The range of the resulting average normal force was from 0.12 to $0.63 \mathrm{~N}$ which can be regarded as light touch conditions $(<1 \mathrm{~N})$ (see Fig. 4) [24]. The stroke length was $30 \mathrm{~mm}$ for all samples. During the tests, the sliding velocity was kept as constant as possible. The sliding velocity of each friction measurement was recorded by the force transducer. In this manner, the data of friction force and normal load were acquired with a sampling rate of $100 \mathrm{~Hz}$. The values of friction coefficient $(\mathrm{COF})$ were calculated as the ratio of friction force $F_{\mathrm{f}}$ and normal load $F_{\mathrm{N}}\left(\mathrm{COF}=\frac{F_{\mathrm{f}}}{F_{\mathrm{N}}}\right)$.

\section{Results and discussion}

\subsection{Friction measurements}

The kinetic friction measurements of all sixteen participants on the stainless steel samples are plotted in Fig. 5, and the average values of COF for the five samples were sorted in decreasing order in Fig. 6. From Fig. 5 it shows that certain participants slide their finger pad with higher values of the friction force than other participants, although the counter

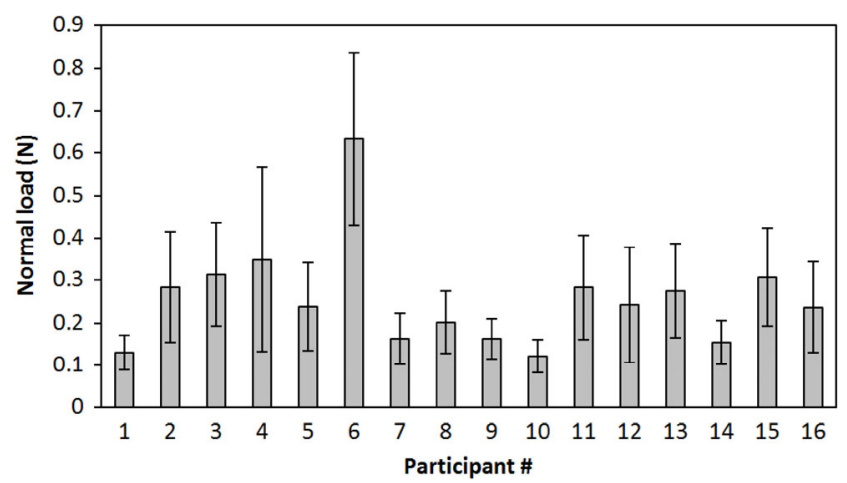

Fig. 4 The average applied normal load (with standard deviation) of each participant during friction measurements.

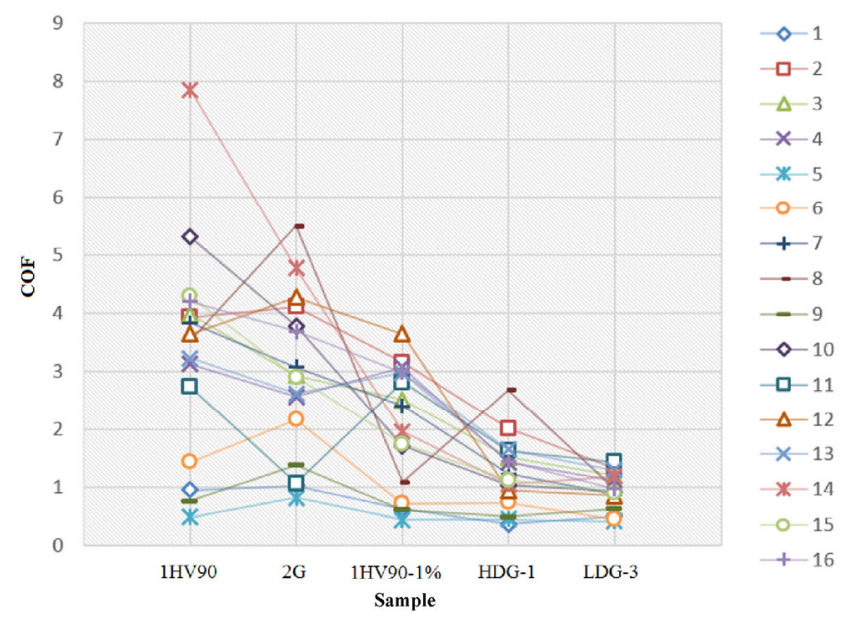

Fig. 5 Finger friction measurements of the participants on the stainless steel samples.

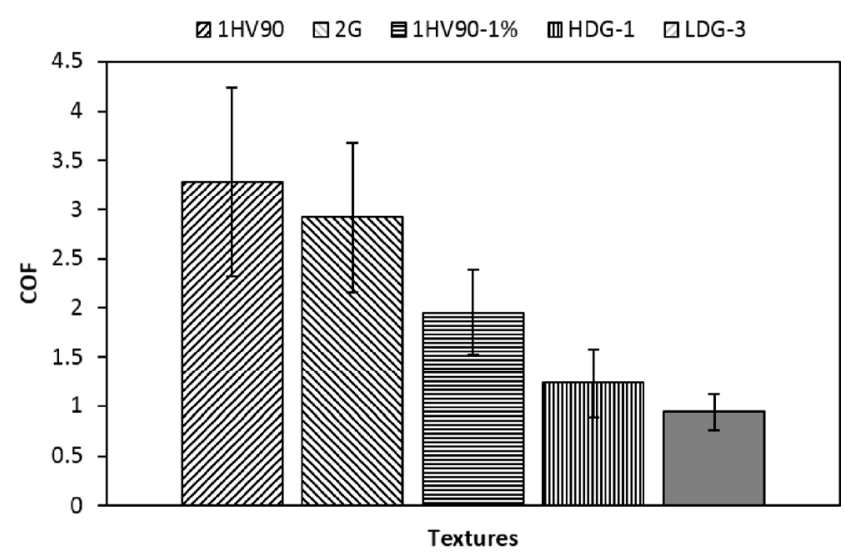

Fig. 6 The average values of $\mathrm{COF}$ of the kinetic friction measurements (five sliding cycles) for the 5 samples, sorted in decreasing order.

surface has the same topography. This phenomenon is related to the system dependence of friction, which could be caused by many factors including the resulting contact area, hydration level of skin, and applied load. These factors can be understood from the welldescribed two-term friction model, for skin friction, which consists of both an adhesive and a deformation component of friction $[25,26]$.

$$
\begin{gathered}
F_{\mathrm{f}, \text { tot }}=F_{\mathrm{f}, \text { adh }}+F_{\mathrm{f}, \text { def }} \\
F_{\mathrm{f}, \text { adh }}=\tau \cdot A_{\text {real }} \\
F_{\mathrm{f}, \text { def }}=\frac{3}{16} \beta \frac{\delta}{a} F
\end{gathered}
$$

where $F$ is the normal load; $A_{\text {real }}$ is the real contact area; $\tau$ is the shear strength of the interface; $a$ is the 
contact radius of the fingertip; $\beta$ is the viscoelastic loss fraction and $\delta$ is the indentation of the skin. Related studies show that adhesive component of friction plays the dominant role in skin friction and greatly depends on the real contact area [27, 28].

The hydration level is another important element of skin friction. Related studies suggest that the increased hydration level of skin can increase the values of COF [29-31], and it is an influential factor in the tactile friction measurement. According to the literature, with the same real contact area, the moist skin has a lower elastic modulus, which leads to the increase of the adhesive component of friction [32]. In our case, the hydration level of all participants ranged from $62 \mathrm{AU}$ to $120 \mathrm{AU}$ with an average value of $90.9 \pm 17.8$ AU. Except for participant \#5 (119.7 AU) and participant \#14 (111.2 AU), the skin type of most participants can be categorized as normal skin (40 100 AU). These two outliers are close to the average value. In this case, the influence of hydration level is limited compared to other factors.

Furthermore, the relationship between the normal load and COF needs to be discussed. In the literature, a linear relationship was found over the load range of $1 \mathrm{~N}[33,34]$. In our case, the overall normal load ranged from $0.13 \mathrm{~N}$ to $0.63 \mathrm{~N}$ with an average normal load of $0.25 \pm 0.12 \mathrm{~N}$, and the lower normal loads were slightly employed with the higher values of $\mathrm{COF}$ (see Fig. 7). Moreover, the sliding velocity can affect the frictional response as well. The force transducer recorded the sliding velocity of each friction measurement, and the sliding velocity of all participants ranged from $25 \mathrm{~mm} / \mathrm{s}$ to $124 \mathrm{~mm} / \mathrm{s}$. According to the research conducted by Tang et al., as the sliding velocity increases, the kinetic tactile friction increases accordingly due to the hysteretic friction with more energy lost in elastic hysteresis [35]. Tang et al. found that values of $\mathrm{COF}$ were larger when sliding velocity increased from $0.5 \mathrm{~mm} / \mathrm{s}$ to $4 \mathrm{~mm} / \mathrm{s}$ and the "stickslip" phenomenon became severer. Therefore, the variations of kinetic skin friction from Fig. 5 can be explained by contact area, hydration level and sliding velocity of each subject. From Fig. 6, it shows that even with the influence described above, certain texture shows higher average value of $\mathrm{COF}$, for example, the texture 1HV90 (crater) has the highest COF compared to others.
More importantly, the surface roughness of the counter-surface was investigated. The measured values of the 3D surface roughness Sa are listed in Table 1 which shows that the laser surface textured samples in general are rougher than both the stamped samples and the reference sample. In this research, the reference stainless steel sample (2G) had the lowest 3D surface roughness Sa. As shown in Fig. 8, a significant reduction in $\mathrm{COF}$ is observed with the sample of higher surface roughness, and illustrating that higher 3D surface roughness Sa result in lower tactile friction with a determination coefficient of 0.8313 . A similar phenomenon was found in the study of Derler [32], that the adhesive component of skin friction is reduced when sliding against a rough glass surface. In our case, the normal load is less than $1 \mathrm{~N}$ which is considered in the light touch regime, therefore, the possible indentation of the skin is relatively smaller than the surface texture under partial contact condition. When in contact with the rougher surface, the skin has a smaller contact area, and lower friction force is generated. Under a constant normal force, the coefficient of friction is reduced significantly, in the current case

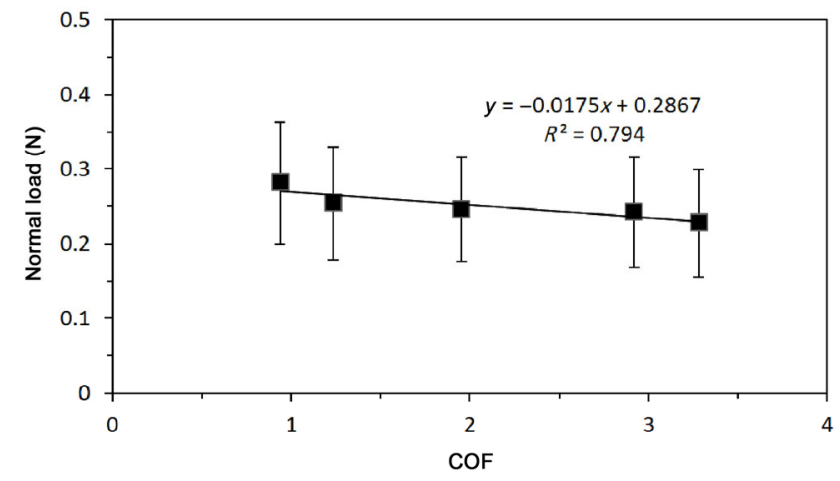

Fig. 7 The average normal load versus COF.

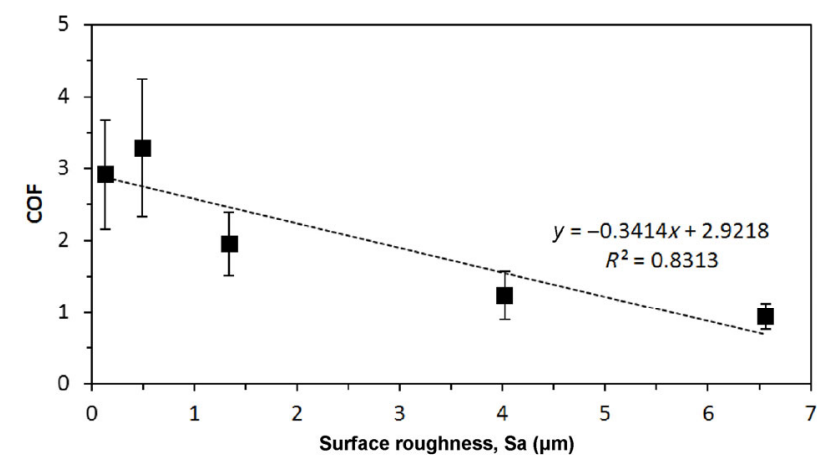

Fig. 8 COF versus measured 3D surface roughness Sa. 
with $250 \%$ reduction compared between the lowest COF with the reference sample.

\subsection{Perceived roughness \& stickiness}

The magnitude estimation method is considered as one of the most common psychophysical methods for the perception experiments. In our case, the perceived roughness and perceived stickiness were ratio scaled by the participants from 0 to 10 based on the intensity of impression towards the stimulus. Compared to the smaller ratio scale like from 1 to 5 , the larger numeric range (from 0 to 10) gave wider perceptual intensity to the individual participants to better describe their natural perception towards the stimulus. In addition, the estimations were then normalized and calculated into the geometric mean.

The perceptual properties of roughness and stickiness are two important elements that contribute to the perception of texture. In this research, the goals of perceived roughness and perceived stickiness were conducted in two parts: (a) perceptual discrimination; and $(b)$ the influence of kinetic tactile friction. As the part (a), we first need to determine whether the participants were able to distinguish the perceptual stimuli like the perceived roughness and perceived stickiness. In our case, the subjects were able to discriminate the perceived stickiness of the samples, and the relationship between the perceived stickiness and 3D surface roughness Sa is in a negative correlation $\left(R^{2}=0.8001\right)$ (see Fig. 9(b)). Moreover, the perceived roughness is consistent with measured $3 \mathrm{D}$ surface roughness $\mathrm{Sa}$, and a positive correlation was found $\left(R^{2}=0.7434\right)$ (see Fig. 9(a)). The results show that the participants can distinguish a set of stainless steel samples in terms of stickiness and roughness. Early research found that subjects were able to discriminate pattern height with difference of $1 \mu \mathrm{m}$ to discriminate the perceived roughness of sandpaper and ridged stainless steel samples with different surface roughness [36]. According to the recent research conducted by Skedung et al., the tactual perception of human finger is able to perceive features of surface textures as small as submicron in both wavelength and amplitude [37]. In our case, the 3D surface roughness Sa was ranged from $0.49 \mu \mathrm{m}$ to $6.56 \mu \mathrm{m}$.

The influences of kinetic tactile friction were also concerned in this study. Figure 9(c) reveals the negative correlation of perceived roughness with the values of COF from the friction measurements $\left(R^{2}=0.7312\right)$. According to the research conducted by Smith et al.,
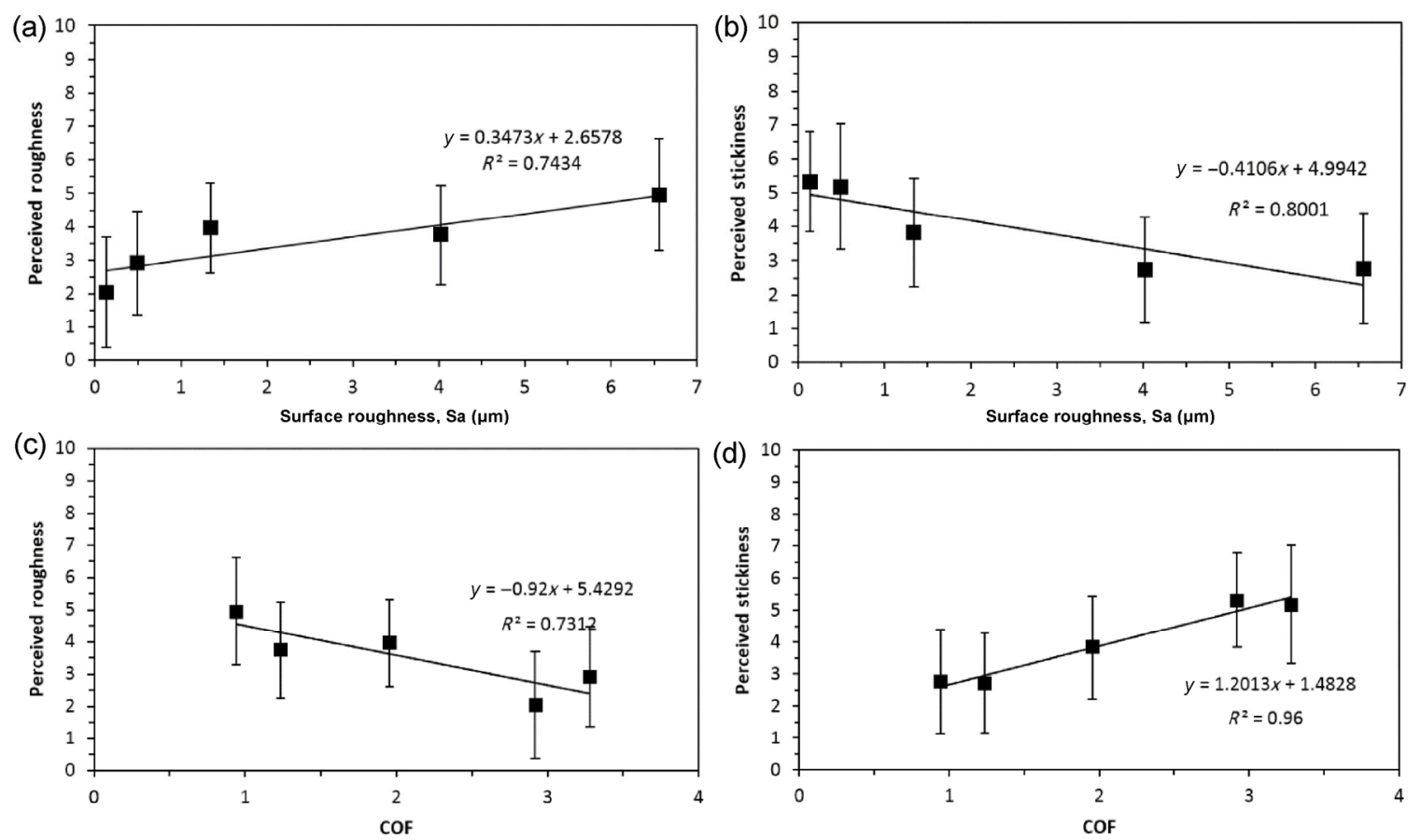

Fig. 9 Geometric mean of perceived roughness versus (a) 3D surface roughness Sa, and (c) COF; and geometric mean of perceived stickiness versus (b) surface roughness $\mathrm{Sa}$, and (d) COF. 
the sensation of roughness (perceived roughness) is a reflection of variation in tangential force [38]. The changes of spacing and height would contribute to the variations in kinetic tactile friction, which ultimately affect the perception of roughness. In Fig. 9(d), the perceived stickiness was found to have a positive correlation with COF $\left(R^{2}=0.96\right)$. The results revealed that the perceived stickiness was significantly influenced by the variation of friction, and similar phenomenon was found in the study of Hollins et al. [39].

\subsection{Comfort Level}

The impression and emotional feeling of an object by touch becomes apparent through sensation, perception and cognition [40]. Moreover, the perception of pleasantness (comfort) is individual, subjective and closely related to the properties of counter-body. From research on multidimensional subjective experience of surface texture, perceptual stimuli of cold-warm, hard-soft, smooth-rough and slippery-sticky can be extracted as four principal subjective dimensions [41-43]. Stainless steel EN-1.4301 was used as the material for all samples, therefore, the perceptual dimension of hard-soft did not apply to this study. Same for the perceptual stimuli of cold-warm, which is same for the same material. In addition, one important physical dimension of kinetic tactile friction was concerned. As such, it becomes possible to explore the relation between the physical stimulus of finger pad friction, and the perceptual stimuli of roughness and stickiness to comfort (or pleasant) touch.

Based on the perception experiments, the relationship between the comfort level and perceived roughness shows no correlation with determination coefficient of 0.2473 (see Fig. 10(a)). This indicates that the perceived roughness is an insignificant stimulus for pleasant touch. According to the literature, the relationship between comfort level and perceived roughness can be biased upon subjects' experiences in tactile sensation [44]. In another study of Barnes et al. [45] on surface and touch, the influence of perception with measured roughness was investigated and no clear relationship was found between roughness and feeling. However, the perceived stickiness shows a negative influence on comfort perception with a rather high coefficient of determination $\left(R^{2}=0.7214\right)$ (see Fig. 10(b)). Based on the results, the sample HDG-1 and sample LDG-3 showed the highest comfort level when the perceived stickiness decreased (See Table 2). It appears that the perceived stickiness is a dominant
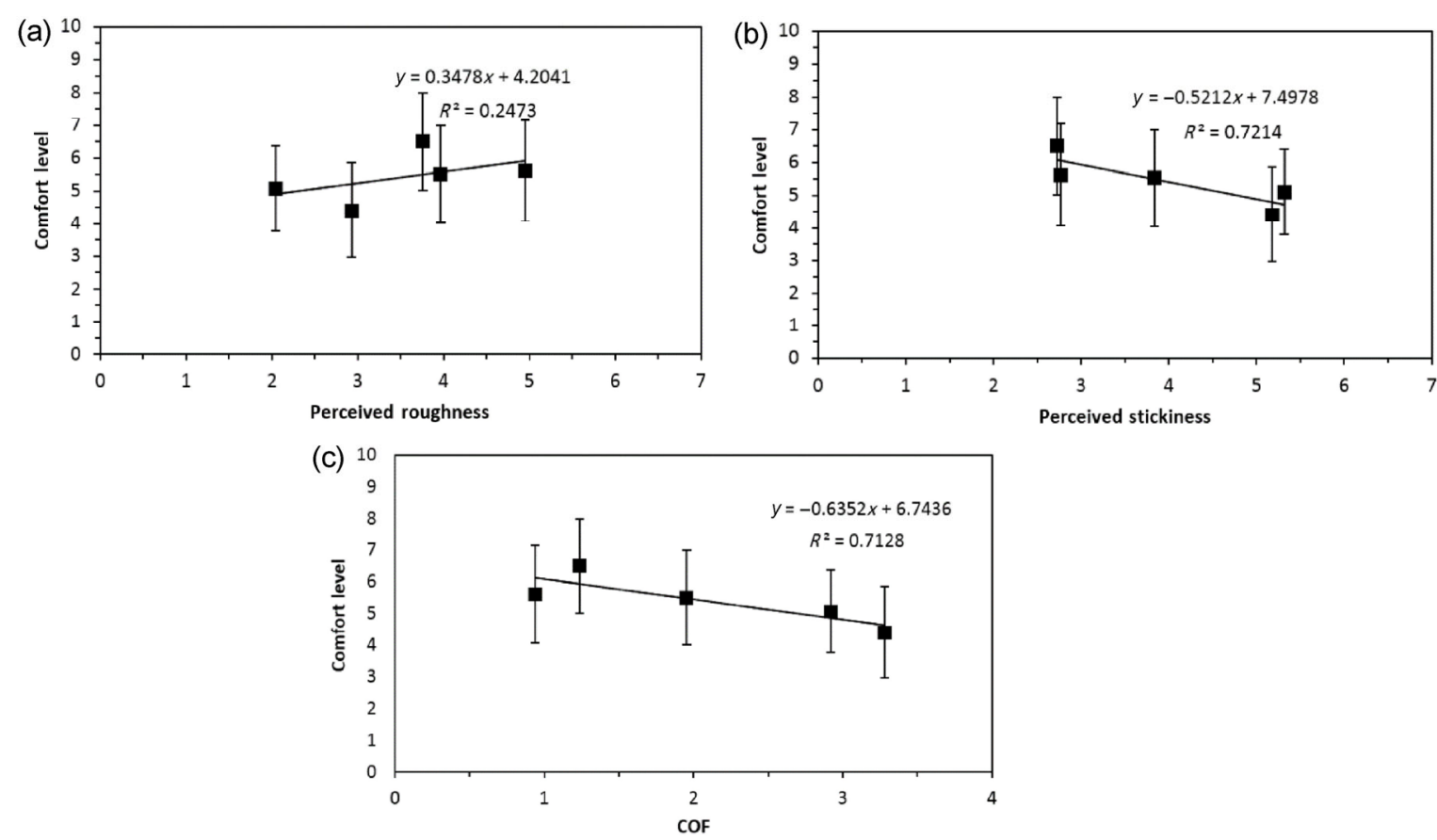

Fig. 10 Geometric mean of (a) comfort level versus perceived roughness; (b) comfort level versus perceived stickiness; (c) comfort level versus $\mathrm{COF}$. 
Table 2 The geometric mean of perceived stickiness, perceived roughness, comfort level of sixteen participants from perception experiments; the average values of COF with standard deviations (STD) from friction measurements.

\begin{tabular}{ccccccccc}
\hline Sample name & Comfort level & STD & $\begin{array}{c}\text { Perceived } \\
\text { stickiness }\end{array}$ & STD & $\begin{array}{c}\text { Perceived } \\
\text { roughness }\end{array}$ & STD & COF & STD \\
\hline HDG-1 & 6.5 & 1.5 & 2.7 & 1.5 & 3.8 & 1.5 & 1.24 & 0.34 \\
LDG-3 & 5.6 & 1.5 & 2.8 & 1.6 & 5.0 & 1.7 & 0.94 & 0.18 \\
1HV90-1\% & 5.5 & 1.5 & 3.8 & 1.6 & 4.0 & 1.3 & 2.03 & 0.49 \\
2G & 5.1 & 1.3 & 5.3 & 1.5 & 2.0 & 1.7 & 2.92 & 0.76 \\
1HV90 & 4.4 & 1.4 & 5.2 & 1.9 & 2.9 & 1.5 & 3.28 & 0.96 \\
\hline
\end{tabular}

perceptual stimulus to affect the level of comfort on the same type of material (same hardness). However, the perceived roughness did not align a meaningful dimension in the comfort level of perception.

In the study on the physical factors influencing pleasant touch, Ref. [7] shows that participants rated comfort level based on the comparison of the friction forces during the perception experiments. In the current case, friction was used as a physical stimulus to the comfort level, based on a crater and grid texture design. From the results, the geometry of grid can change the surface roughness greatly and had a better effect in reducing the kinetic skin friction compared to the crater structure and reference sample. A clear negative correlation was found between the level of comfort and the COF with the determination coefficient of 0.7128 (see Fig. 10(c)). The comfort level increases when the tactile friction between the skin and counter-surface decreases which is consistent with the experimental results of Klöcker et al. [7]. Therefore, the kinetic tactile friction can be concluded as a physical stimulus to predict the comfort feeling based on the experimental data. And grid structure is one unique and desired texture to create high comfort touch conditions.

\section{Conclusions}

In this research, subjective and objective measurements were performed by sixteen participants on five different stainless steel samples with designed microstructured surfaces. Based on the results of perception tests (subjective measurements) and friction measurements (objective measurements), the conclusions can be summarized as follows:
(1) The participants had the ability to distinguish the perceived roughness and stickiness of the countersurface by touching the objects in sliding motion. The perceived roughness was consistent with 3D surface roughness Sa in a positive correlation. And the perceived stickiness was found to correlate in a negative relationship with 3D surface roughness Sa. In addition, both perception of stickiness and roughness can be influenced by the variation of kinetic tactile friction.

(2) From the subjective perspective, the perceived stickiness was illustrated as a perceptual stimulus which was able to influence the comfort level of perception in a negative correlation. However, the effect of the perceived roughness was insignificant in the connection to the perception of comfort.

(3) From the objective perspective, the kinetic tactile friction was proved to be an effective physical stimulus which has a negative correlation to the comfort perception.

The results of this study can be beneficial to understand the relationship between the tactile friction and perceptual attributes including perceived roughness, perceived stickiness and comfort level. In the future research, the effect of temperature on tactile friction and perception will be investigated.

\section{Acknowledgments}

This work was supported by the Research Programme of the Research Fund for Coal and Steel, under Contract No. RFSR-CT-2011-00022.

Open Access: The articles published in this journal are distributed under the terms of the Creative Commons Attribution 4.0 International License (http:// 
creativecommons.org/licenses/by/4.0/), which permits unrestricted use, distribution, and reproduction in any medium, provided you give appropriate credit to the original author(s) and the source, provide a link to the Creative Commons license, and indicate if changes were made.

\section{References}

[1] Schreiner S, Rechberger M, Bertling J. Haptic perception of friction-Correlation friction measurements of skin against polymer surfaces with subjective evaluations of the surfaces' grip. Tribology International 63: 21-28 (2011)

[2] Tang W, Bhushan B. Adhesion, friction and wear characterization of skin and skin cream using atomic force microscope. Colloids and Surfaces B: Biointerfaces 76: $1-15$ (2010)

[3] Harih G, Dolsak B. Tool-handle design based on a digital human hand model. International Journal of Industrial Ergonomics 43(4): 288-295 (2013)

[4] Kuijt-Evers L F M, Groenesteijn L, de Looze M P, Vink P. Identifying factors of comfort in using hand tools. Applied Ergonomics 35: 453-458 (2004)

[5] Kuijt-Evers L F M, Vink P, de Looze M P. Comfort predictors for different kinds of hand tools: Differences and similarities. International Journal of Industrial Ergonomics 37: 73-84 (2006)

[6] Ramalho A, Szekeres P, Fernandes E. Friction and tactile perception of textile fabrics. Tribology International 63: 29-33 (2013)

[7] Klöcker A, Oddo CM, Camboni D, Penta M, Thonnard J L. Physical factors influencing pleasant touch during passive fingertip stimulation. PLOSONE 9(7): e101361 (2014)

[8] Haggard P. Sensory neuroscience: from skin to object in the somatosensory cortex. Current Biology 20: 884-886 (2006)

[9] Nakanishi Y. Hydrated Materials: Applications in Biomedicine and the Environment. Singapore: Pan Stanford Publishing Pte. Ltd, 2015.

[10] Lapière C M. The ageing dermis: The main cause for the appearance of "old" skin. British Journal of Dermatology 122: 5-11 (1990)

[11] Hendriks C P, Franklin S E. Influence of surface roughness, material and climate conditions on the friction of human skin. Tribology Letters 37: 361-373 (2010)

[12] Derler, S, Huber R, Feuz H P, Hadad M. Influence of surface microstructure on the sliding friction of plantar skin against hard substrates. Wear 267: 1281-1288 (2009)

[13] Diridollou S, Vabre V, Berson M, Vaillant L, Black D,
Lagarde J M, Grégoire J M, Gall Y, Patat F. Skin ageing: changes of physical properties of human skin in vivo. International Journal of Cosmetic Science 23: 353-362 (2001)

[14] Cua A B, Wilhelm K P, Maibach H I. Frictional properties of human skin: relation to age, sex and anatomical region, stratum corneum hydration and trans epidermal water loss. British Journal of Dermatology 123: 473-479 (1990)

[15] Veijgen N K, Masen M A, van der Heide E. Relating friction on the human skin to the hydration and temperature of the skin. Tribology Letters 49: 251-261 (2013)

[16] Tomlinson S E, Carré M J, Lewis R, Franklin S E. Human finger contact with small, triangular ridged surfaces. Wear 271(9-10): 2346-2353 (2011)

[17] Tomlinson S E, Lewis R, Carré M J, Franklin S E. Human finger friction in contacts with ridged surfaces. Wear 301(1-2): 330-337 (2013)

[18] Bensmaia S, Manfredi L. The sense of touch. Encyclopedia of Human Behavior 2: 379-386 (2012)

[19] Heinrich U, Koop U, Leneveu-Duchemin M C, Osterrieder K, Bielfeldt S, Chkarnat C, Degwert J, Hantschel D, Jaspers S, Nissen H P, Rohr M, Schneider G, Tronnier H. Multicentre comparison of skin hydration in terms of physical-, physiological- and product-dependent parameters by the capacitive method. International Journal of Cosmetic Science 25: 45-53 (2003)

[20] Durakbasa M N, Osanna P H, Demircioglu P. The factors affecting surface roughness measurements of the machined flat and spherical surface structures-The geometry and the precision of the surface. Measurement 44(10): 1986-1999 (2011)

[21] van der Heide E, Saenz de Viteri V, Rodringuez-Vidal E, Pagano F, Wadman B, Wiklund D, Matthews D T A, Contreras Fortes J, Zhang S. Steel Sheet Surfaces with Enhanced Tactile Feel. Luxembourg: RFCS Publications, 2016.

[22] Whitaker T, Simoes-Franklin C, Newell N F. Vision and touch: independent or integrated systmens for the perception of Texture. Brain Research 1242: 59-72 (2008)

[23] Zhang S, Rodriguez Urribarri A, Morales Hurtado M, Zeng $\mathrm{X}$, van der Heide $\mathrm{E}$. The role of the sliding direction against a grooved channel texture on tool steel: An experimental study on tactile friction. International Journal of Solids and Structures 56-57: 53-61 (2015)

[24] Lackner J R, Dizio P, Jeka J, Horak F, Krebs D, Rabin E. Precision contact of the fingertip reduces postural sway on individuals with bilateral vestibular loss. Experimental Brain Research 126: 459-466 (1999)

[25] Adams M J, Briscoe B J, Johnson S A. Friction and Lubrication of Human Skin. Tribology Letters 26(3): 239-253 (2007) 
[26] Duvefelt K, Olofsson U, Johannesson C M, Skedung L. Model for contact between finger and sinusoidal plane to evaluate adhesion and deformation component of friction. Tribology International 96: 389-394 (2016)

[27] Greenwood J A, Tabor D. The friction of hard sliders on lubricated rubber: The importance of deformation losses. Proceedings of the Physical Society 71(6): 989-1001 (1958)

[28] Johnson S A, Gorman D M, Adams M J, Briscoe M J. The friction and lubrication of human stratum corneum. In Proceedings 19th Leeds-Lyon Symposium on Tribology, Leeds, UK, 1993: 663-672.

[29] El-Shimi A F. In vivo skin friction measurements. Journal of the Society of Cosmetic Chemists 28: 37-51 (1977)

[30] Comaish S, Bottoms E. The skin and friction: deviations from Amonton's laws, and the effects if hydration and lubrication. British Journal of Dermatology 84: 37-43 (1971)

[31] Nacht S, Close J, Yeung D, Gans E H. Skin friction coefficient: Changes induced by skin hydration and emollient application and correlation with perceived skin feel. Journal of the Society of Cosmetic Chemists 32: 55-65 (1981)

[32] Derler S, Gerhardt L C, Lenz A, Bertaux E, Hadad M. Friction of human skin against smooth and rough glass as a function of the contact pressure. Tribology International 42: 1565-1574 (2009)

[33] Childs T H C, Henson B. Human tactile perception of screen-printed surfaces: Self-report and contact mechanics experiments. Proc IMechE, Part J: J Engineering Tribology 221: 427-441 (2007)

[34] Skedung L, Danerlov K, Olofsson U, Aikala M, Niemi K, Kettle J. Finger-friction measurements on coated and uncoated printing papers. Tribology Letters 37: 389-399 (2010)

[35] Tang W, Ge S, Zhu H, Cao X, Li N. The influence of normal load and sliding speed on frictional properties of skin. Journal of Bionic Engineering 5: 33-38 (2008)

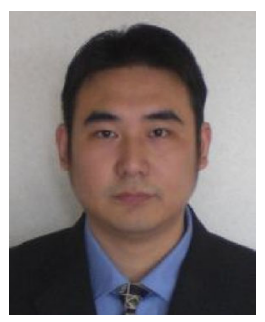

Sheng ZHANG. He received his bachelor degree in mechanical engineering in 2008 from California State University (USA), and obtained his Ph.D degree in mechanical
[36] Miyaoka T, Mano T, Ohka M. Mechanisms of fine-surfacetexture discrimination in human tactile sensation. Journal of the Acoustical Society of America 105: 2485-2492 (1999)

[37] Skedung L, Arvidsson M, Chung J Y, Stafford C M, Berglund B, Rutland M W. Feeling small: exploring the tactile perception limits. Scientific Reports 3: 1-6 (2013)

[38] Smith A M, Chapman C E, Deslandes M, Langlais J S, Thibodeau M P. Role of friction and tangential force variation in the subjective scaling of tactile roughness. Experimental Brain Research 144: 211-223 (2002)

[39] Hollins M, Lorenz F, Seeger A, Taylor R. Factors contributing to the integration of textural qualities: Evidence from virtual surfaces. Somatosensory and Motor Research 22(3): 193-206 (2005)

[40] Lui X, Yue Z, Cai Z, Chetwynd D G, Smith S T. Quantifying touch-feel perception: tribological aspects. Measurement Science and Technology 19(8):817-822 (2008)

[41] Skedung L, Danerlov K, Olofsson U, Johannesson C M, Aikala M, Kettle J, Arvidsson M, Berglund B, Rutland M W. Tactile perception: Finger friction, surface roughness and perceived coarseness. Tribology International 44: 505-512 (2011)

[42] Hollins M, Faldowski R, Rao S, Young F. Perceptual dimensions of tactile surface texture: a multidimensional scaling analysis. Perception \& Psychophysics 54: 697-705 (1993)

[43] Picard D, Dacremont C, Valentin D, Giboreau A. Perceptual dimensions of tactile textures. Acta Psychologicaol 114: 165-184 (2003)

[44] Annett J. Subjective rating scales: science or art. Ergonomics 45: 966-987 (2002)

[45] Barnes C J, Childs T H C, Henson B, Southee C H. Surface finish and touch-a case study in a new human factors tribology. Wear 257: 740-750 (2004)

engineering at University of Twente (the Netherlands) in 2016. His current position is a post-doctoral researcher in the State Key Laboratory of Tribology at Tsinghua University. His research interests include bio-tribology and surface texture design. 


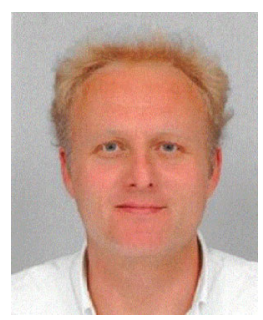

Emile VAN DER HEIDE. He obtained his M.Sc. and Ph.D degrees in mechanical engineering from University of Twente in 1995 and 2002. His current position is a professor, chair of Skin Tribology,
Laboratory for Surface Technology and Tribology, Faculty of Engineering Technology, University of Twente. He has received President's International Fellowship 2016/17 from Chinese Academy of Sciences. His research areas cover the surface engineering, bio-tribology and contact mechanics. 